\title{
Inercia, llegando a la academia
}

$\mathrm{C}$ on el continuo y casi despiadado crecimiento del conocimiento científico, en el que la cantidad de información que debemos leer para mantenernos actualizados sobrepasa lo posible, la probabilidad de caer en franjas de desconocimiento es bastante alta. Luego el problema no es realmente la velocidad de crecimiento de información, ni el tiempo disponible para leerla, tal vez el problema radica en poder discernir lo útil, de lo interesante.

Uno de los principales detonantes de esta condición es lo que he llamado la inercia académica, donde se juega en condiciones adversas para poder combatirla. Este estado en el cual la academia cae, está dado por un carencia en innovación de currículo o falta de detección de movimientos científicos (inteligencia de mercado).

En este tema en especial se ha sacrificado la endocrinología, la cual de forma consistente se ha ubicado en espacios dejados por áreas tal vez más tendenciosas o vistosas. Es así como en pregrado generalmente se asocia la educación en endocrinología a temas como diabetes y enfermedad tiroidea; posteriormente en posgrado, cuando se trata de ramas con conexión hormonal, en el mejor de los casos asisten a dos meses de rotación por endocrinología.

Si esto lo ponemos en perspectiva y tomamos datos de la OMS, donde el 30\% de la población mundial padece de obesidad, el 9,2\% tiene hipercolesterolemia, el 8,4\% presenta diabetes tipo 2 y $7 \%$ presenta trastornos de la función tiroidea, podemos entonces considerar el porqué debemos pensar que las escuelas de medicina presentan una "inercia académica". Inclusive debemos atrevernos a preguntarnos ¿qué estamos enseñando?, ¿por qué lo estamos enseñando? y ¿es pertinente lo que se ha enseñado?

Si hacemos estas preguntas hacia la patología de mayor prevalencia mencionada anteriormente, tal vez el problema que enfrentamos hoy no va a ser de fácil abordaje, pues tenemos mucho personal médico que aún considera a la obesidad como un tema estético, o descuido personal, o simplemente irrelevante. Lamentablemente muchos pacientes piensan de igual forma, siendo no menos importante preguntar, ¿qué piensan los aseguradores sobre la obesidad?
La obesidad es una entidad discriminada, posiblemente secundaria a la misma desinformación que se tiene de ella, porque desde nuestro ADN académico, nunca la vimos como enfermedad per se.

Actualmente, entre las áreas de crecimiento académico más generoso está la obesidad, pues incluye aspectos psicoemocionales, sociales, epigenéticos, ambientales, moleculares, endocrinológicos, cardiovasculares, renales, oncológicos, ortopédicos y neurológicos por no seguir mencionando cada uno de los aspectos con los cuales se relaciona.

Aún no tenemos claridad por dónde empezar, cómo abordarla, cómo manejarla y mantenerla, de ahí que la educación no formal en este tema haya crecido de forma vertiginosa, con indolencia de las facultades de medicina, aunque un poco coaccionados por los entes gubernamentales que buscan limitar nuevos programas de educación, generando una ola de grandes oportunidades económicas sin rigor científico que puedan llenar o responder a las reales necesidades de salud pública que demanda esta patología.

Es aquí donde la visión y la importancia de los gremios debe mostrarse, con gran ejemplo demostrado por la ACE, que en su congreso internacional, al respecto de la obesidad, cubrió gran parte de la agenda académica, al igual que en cada uno de los capítulos que promueven de forma continua la educación en esta especial patología, pero tristemente sabemos que no es suficiente para poder abarcar esta gran problemática.

Esta reflexión espera ubicar a los principales tomadores de decisiones en las facultades de medicina y directores de programas, pues es una obligación educar a nuestros estudiantes con conocimientos profundos, en áreas de mayor necesidad para el entorno social en donde se van a desempeñar.

\section{Ricardo Rosero Revelo}

Médico Internista - Endocrinólogo

Miembro de Número ACE

Clínica Las Américas 